\title{
Electrochemical Study of Charge Transfer in Conducting Polymers
}

\author{
J.M. Pernaut, L.C. Soares, and J.C. Belchior \\ Departamento de Química, ICEx Universidade Federal de Minas Gerais, C.P. 702, \\ 31270-901 Belo Horizonte - MG, Brazil
}

Recieved: June 30, 1996; January 9, 1997

\begin{abstract}
Aspectos cinético e termodinâmico da transferência de carga em polímeros condutores foram investigados. Um modelo de difusão restrita foi impregado para interpretar os dados obtidos por cronopotenciometria com pulso. Em filmes de poli 3-metiltiofeno, o coeficiente de difusão aparente diminuiu em função da espessura do filme mas ficou constante com a concentração eletrolítica. Em filmes finos, usando-se voltametria cíclica, caracterizou-se mudanças termodinâmicas, como em particular, a deconvolução das duas transferências eletrônicas envolvidas no processo. Usando-se um modelo nernstiano incluindo potenciais de interação, conseguiu-se descrever a reação para as duas etapas eletroquímicas. Finalmente, como esperado, uma correlação entre o raio iônico dos dopantes e o coeficiente de difusão aparente foi estabelecida em filmes de polipirrol.
\end{abstract}

The kinetics and thermodynamic aspects of charge transfer in conducting polymers were investigated. A restricted diffusion model was used to analyze kinetic data obtained from pulse-chronopotentiometric experiments. In poly 3-methylthiophene, the apparent diffusion coefficient decreased with the film thickness, whereas it remained constant with the electrolyte concentration. In thin films, thermodynamic changes were characterized by cyclic voltammetry, specifically, the deconvolution of the two electronic transfers involved in the process. Using a Nernstian model including interaction potentials, the two electrochemical steps were well described. Finally, as expected, a correlation between the ionic radius of the dopants and the apparent diffusion coefficient was established in polypyrrole films.

Keywords: conducting polymer, charge transfer, chronopotentiometry, diffusion

\section{Introduction}

Conducting polymers belong to a class of quite versatile $^{1}$ materials of interest because of their prospect in technological applications ${ }^{2}$. The insulator/conductor transition plays a fundamental role which motivates the study of the redox reaction in these materials (charge transfer and accumulation), in order to determine parameters such as doping level, reversibility, or kinetic factors.

The difficulty in understanding the properties of these materials comes from the fact that the work is usually carried out on polymers with variable structures, using different characterization techniques, some of which are not very suitable for these purposes. It is generally recognized that in all kinds of conducting polymers the oxido-reduction reaction is equivalent to a two-step electrochemical process that does not follow the Nernst model. It is commonly at- tributed to high intersite interactions and other non-ideality factors $^{3}$. On the other hand, it is also known that a simple kinetic model of diffusion does not exactly fit the doping process of the electroactive films. This is mainly because the polymer suffers a large phase transition during the reaction (conformation, electrical conductivity) which moves the reactional interface from the electrode/polymer region to the polymer/electrolyte one, bringing about in a significant change in the dimensionality of the diffusion ${ }^{4}$.

This work aims to investigate the thermodynamic and kinetic aspects of the redox reaction of conducting polymers, varying the structure and the doping conditions and choosing suitable methods of analysis. Polypyrrole (PPy) and poly 3-methyl (P-3MeT) were chosen as the materials to be studied in aqueous and organic media, respectively. The polymerization was performed in different ways, namely, galvanostatically, potentiostatically, and 
potentiodynamically. Films of various thicknesses were synthesized, and the concentration and the nature of the electrolyte salt were changed.

Low speed cyclic voltammetry was used as a tool for determining the formal potential, the electrochemical doping level, and the reversibilty grade of the reaction. Interaction potentials were calculated in some specific cases using an interaction redox model $^{5}$. An apparent diffusion coefficient $\left(D_{a p}\right)$ was deduced from higher speed experiments, plotting $\mathrm{i}$ vs. $\mathrm{v}^{1 / 2}$. The morphological aspect of the films was controlled by electronic microscopy, and the doping level was also evaluated by microprobe experiments. A small amplitude method, pulse chronopotentiometry, was peformed on reduced films to measure the apparent diffusion coefficient without disturbing the structure of the polymer. A restricted linear diffusion model was used to fit the potential-time plots.

\section{Experimental}

\section{Materials}

Pyrrole 98\%, sodium dodecylsulfate (DSNa), 3-methyl thiophene, bithiophene, terthiophene, $+95 \%$ lithium perchlorate, and acetonitrile $+99.9 \%$ HPLC grade were commercial Aldrich products. Potassium chloride, lithium chloride, sodium chloride, and cesium chloride were purchased from VETEC (Brazil). All products were used as received.

\section{Electrochemical measurements}

All electrochemical experiments were carried out at room temperature under argon atmosphere using equipment from Autolab/Ecochemie. A one compartment Metrohm-type electrochemical cell was used with a saturated calomel electrode (SCE) as a reference (equipped with a saline bridge for organic media), a platinum wire as an auxiliary electrode, and a platinum working electrode with an apparent surface of $8 \times 10^{-3} \mathrm{~cm}^{2}$. A concentration of $0.1 \mathrm{~mol} / \mathrm{L}$ was used in standard experiments for both monomer and electrolytes. For organic solutions, after preparation, the solution was dried with molecular sieves $(3 \AA)$ and filtered before use. Before each experiment, the working electrode was polished with neutral alumina and washed with distilled water. Electrosynthesis of PPy and P3MeT films was performed galvanostatically using a current density of $1 \mathrm{~mA} / \mathrm{cm}^{2}$.The PPy films were prepared in aqueous solutions containing sodium dodecylsulfate (DSNa) as the electrolyte, and P3MeTh in acetonitrile solutions containing $\mathrm{LiClO}_{4}$ as electrolyte. After electrosynthesis, a potential of $0 \mathrm{~V}$ was applied to the PPy film and $0.7 \mathrm{~V}$ to the P3MeTh film until the current decreased below $1 \mu \mathrm{A}$; then the polymer was rinsed several times with water (PPy) or acetonitrile (P3MeT) and dipped in the working electrolyte. With regard to the computational aspects, simulations were performed on an IBM RISC/6000, model 3CT, for kinetic data, and on a $486 \mathrm{DX} 2 \mathrm{PC}$ for thermodynamic data.

\section{Results and Discussions}

\section{Monomer reactivity}

The voltammetric oxidation of some monomers is presented in Fig. 1. As expected, the reaction is irreversible at this potential sweeping speed; the anodic displacement of the peak potential from the terthiophene to the thiophene is related to the length of the conjugation, which is inversely proportional to the ionization potential ${ }^{6}$. For experimental convenience, pyrrole and 3-Me thiophene were chosen for a study in aqueous and organic media, respectively.

\section{Polymerization modes}

For the same polymerization speed, the potentiostatic and galvanostatic modes are roughly equivalent. The latter was systematically used in this study in order to achieve better control of the charge density. Furthermore, small current densities (less than $1 \mathrm{~mA} \mathrm{~cm}^{-2}$ ) were preferred, since earlier studies have shown that these mild free monomer diffusion conditions provide denser and more regular films ${ }^{7}$. Pulsed current polymerization was also applied, but the results are not presented here. Actually, as this mode of synthesis undoubtedly leads to more compact and adherent films ${ }^{7}$, it was found that the reversibility of the redox process of the films decreased and the thickness could not be simply related to the polymerization charge ${ }^{8}$.

\section{Redox properties of the polymer films}

The thermodynamic aspect

As pointed out in the Introduction, these data come from low speed cyclic voltammetry where diffusion is assumed to not interfere. The redox process is assimilated to

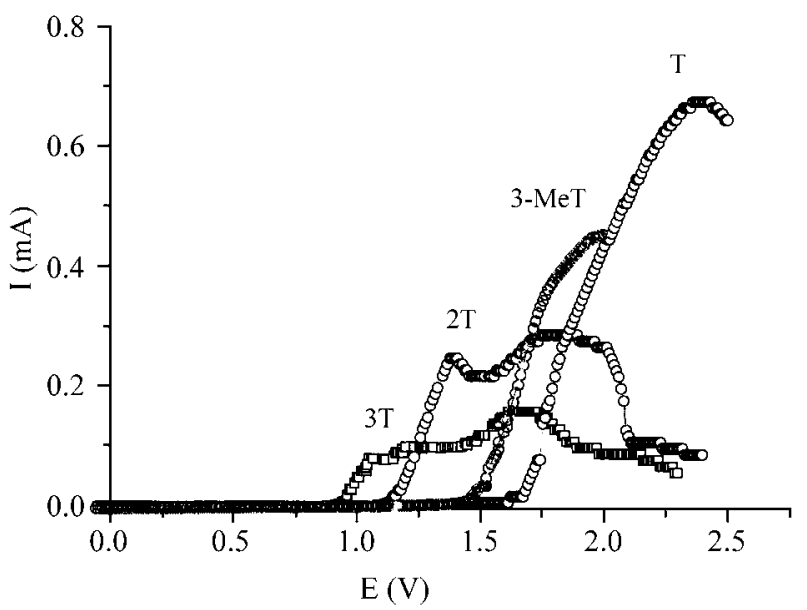

Figure 1. Voltammograms of the electro-oxidation of some monomers: $0.2 \mathrm{~mol} / \mathrm{L}$ thiophene $(\mathrm{T}), 0.1 \mathrm{~mol} / \mathrm{L}$ 3-methyl thiophene (3-MeT), $0.1 \mathrm{~mol} / \mathrm{L}$ bithiophene (2T), $0.06 \mathrm{~mol} / \mathrm{L}$ terthiophene (3T) in acetonitrile, $0.1 \mathrm{~mol} / \mathrm{L} \mathrm{LiClO}_{4} \mathrm{v}=10 \mathrm{mV} / \mathrm{s}$. 

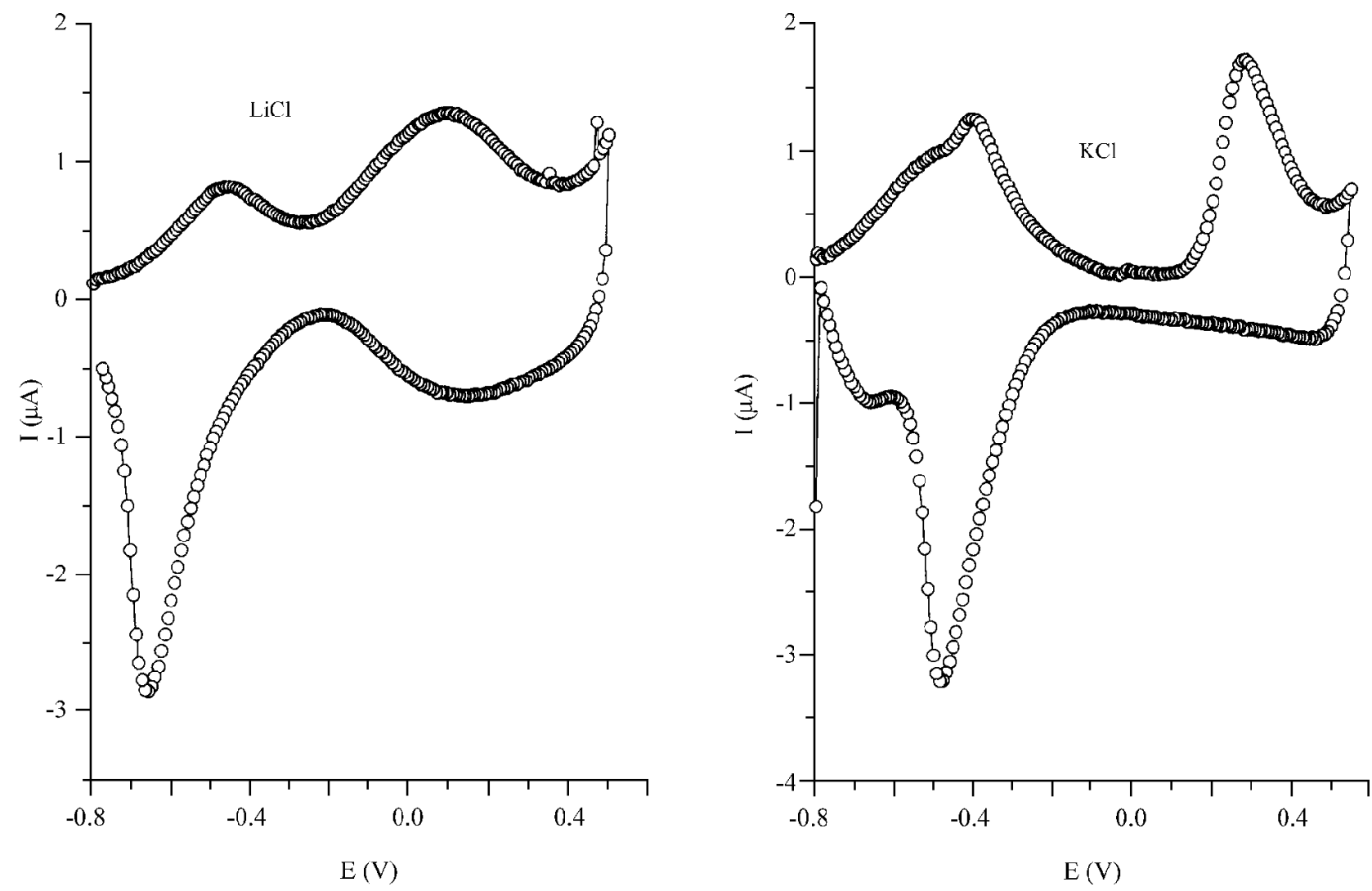

Figure 2. Cyclic voltammograms $(10 \mathrm{mV} / \mathrm{s})$ of PPy films $\left(1 \mathrm{~mA} / \mathrm{cm}^{2}\right)$ in $0.1 \mathrm{~mol} / \mathrm{L}$ aqueous solutions of (2-a) $\mathrm{LiCl}$ and (2-b) $\mathrm{KCl}$.

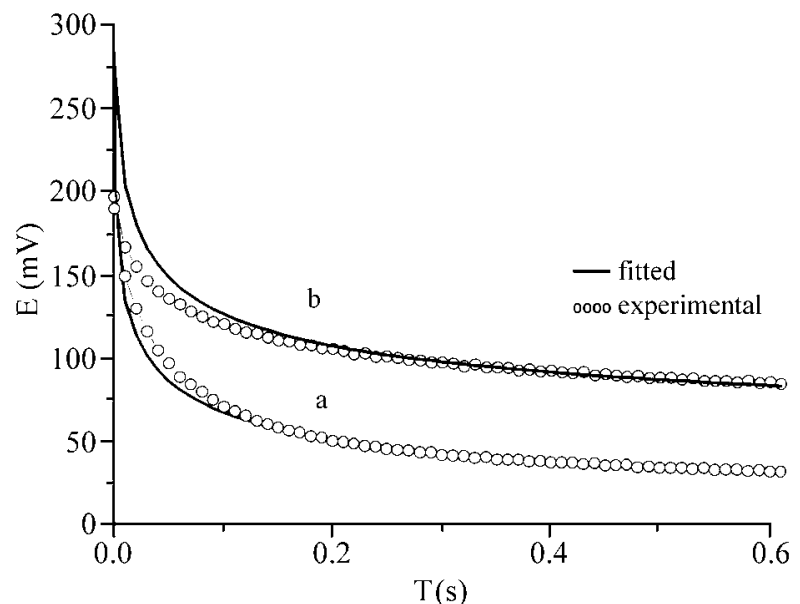

Figure 3. A comparison between simulated and experimental chronopotentiograms $\left(\tau=0.1 \mathrm{~s}, \mathrm{i}_{\mathrm{p}}=400 \mu \mathrm{A} / \mathrm{cm}^{2}\right)$ of PPy films $(0.48$ $\mu \mathrm{m})$ in $0.1 \mathrm{~mol} / \mathrm{L}$ aqueous solutions of (a) $\mathrm{LiCl}\left(\mathrm{D}_{\mathrm{ap}}=4.5 \times 10^{-12}\right.$ $\mathrm{cm} / \mathrm{s})$ and $(\mathrm{b}) \mathrm{KCl}\left(\mathrm{D}_{\mathrm{ap}}=1 \times 10^{-11} \mathrm{~cm} / \mathrm{s}\right)$.

two monoelectronic transfers between three species, neutral (PP), cation radical $\left(\mathrm{PP}^{+}\right)$, and dication $\left(\mathrm{PP}^{++}\right)$, each one chemically equivalent to six monomer moieties.

The modified Nernst equation is ${ }^{5}$ :

$$
\begin{aligned}
& \mathrm{E}=\mathrm{E}_{1}^{0}+\frac{\mathrm{RT}}{\mathrm{F}} \ln \frac{\mathrm{C}\left(\mathrm{PP}^{+}\right)}{\mathrm{C}(\mathrm{PP})}+\frac{\Delta \mu\left(\mathrm{PP}^{++}\right)-\Delta \mu\left(\mathrm{PP}^{+}\right)}{\mathrm{F}} \\
& \mathrm{E}=\mathrm{E}_{2}^{0}+\frac{\mathrm{RT}}{\mathrm{F}} \ln \frac{\mathrm{C}\left(\mathrm{PP}^{++}\right)}{\mathrm{C}\left(\mathrm{PP}^{+}\right)}+\frac{\Delta \mu\left(\mathrm{PP}^{++}\right)-\Delta \mu\left(\mathrm{PP}^{+}\right)}{\mathrm{F}}
\end{aligned}
$$

where the interaction potentials have a classic linear dependence on concentration:

$$
\begin{aligned}
& \frac{\Delta \mu\left(\mathrm{PP}^{+}\right)}{\mathrm{F}}=\mathrm{B}_{11} \frac{\mathrm{C}\left(\mathrm{PP}^{+}\right)}{\mathrm{C}_{\mathrm{T}}}+\mathrm{B}_{12} \frac{\mathrm{C}\left(\mathrm{PP}^{++}\right)}{\mathrm{C}_{\mathrm{T}}} \\
& \frac{\Delta \mu\left(\mathrm{PP}^{++}\right)}{\mathrm{F}}=\mathrm{B}_{21} \frac{\mathrm{C}\left(\mathrm{PP}^{+}\right)}{\mathrm{C}_{\mathrm{T}}}+\mathrm{B}_{22} \frac{\mathrm{C}\left(\mathrm{PP}^{++}\right)}{\mathrm{C}_{\mathrm{T}}}
\end{aligned}
$$

where $\mathrm{C}_{\mathrm{T}}=\mathrm{C}(\mathrm{PP})+\mathrm{C}\left(\mathrm{PP}^{+}\right)+\mathrm{C}\left(\mathrm{PP}^{++}\right)$. The equation system was solved using Newton's algorithm, and the program for generating simulated voltammograms was written in Basic/Windows. Some typical results are shown in Fig. 5.

The kinetic aspect

Data from pulse-chronopotentiometry may be, in principle, more reliable than others from large amplitude methods (for example double-step chronoamperometry). This occurs owing to the fact that the pulse is applied on a 
potentiostatically equilibrated film in its reduced state. This means that the polymer properties does not change significantly during the injection of a small quantity of charge and behaves as a redox polymer ${ }^{9}$ in its reduced state. In this case, it can be assumed that the kinetics of change transfer is of the diffusional type and that it is controlled by ionic motion rather than self-exchange electrons ${ }^{10}$. Another important point is that the measurement is performed in an open circuit, so that it can be assumed that no migration contribution is included in the ionic mobility.

The method consists of injecting a small current pulse into the reduced film in order to create some oxidized sites, and then to follow the open circuit potential $\left(\mathrm{E}_{\mathrm{oc}}\right)$ as a function of time. The transient concentration at the electrode $(\mathrm{C}(0, \mathrm{t}))$-time can be calculated from finite linear diffusion equations. The initial profile, $\mathrm{C}(\mathrm{x}, \mathrm{t})$, is calculated assuming a planar source of diffusing species, since the interface is located at the electrode ${ }^{11}$

$$
\begin{aligned}
C\left(x^{\prime}, \tau\right)=2 \frac{i p}{n F}\left[\frac{\tau}{\pi D_{a p}}\right]^{1 / 2} & \exp \left[\frac{-x^{, 2}}{4 D_{a p} \tau}\right]- \\
& -\frac{i_{p} x}{n F D_{a p}} \operatorname{erfc}\left[\frac{x}{2\left(D_{a p} \tau\right)^{0.5}}\right]
\end{aligned}
$$

where $\tau$ is the pulse duration, $i_{p}$ the current density of the pulse, $n$ the number of electrons (1e/PP), and $F$ the faraday constant.

After termination of the current pulse, the distribution of the diffusion species at the electrode surface as a function of time is given by ${ }^{11}$ :

$$
\begin{array}{r}
C(x, t)=C f+\frac{2}{L} \sum_{n=1}^{\infty} \exp \left[\frac{-D_{a p} n^{2} \pi^{2} t}{L^{2}}\right] \cos \left[\frac{n \pi x}{L}\right] \\
\int_{0}^{L} C\left(x^{\prime}, \tau\right) \cos \left[\frac{n \pi x^{\prime}}{L}\right] d x,
\end{array}
$$

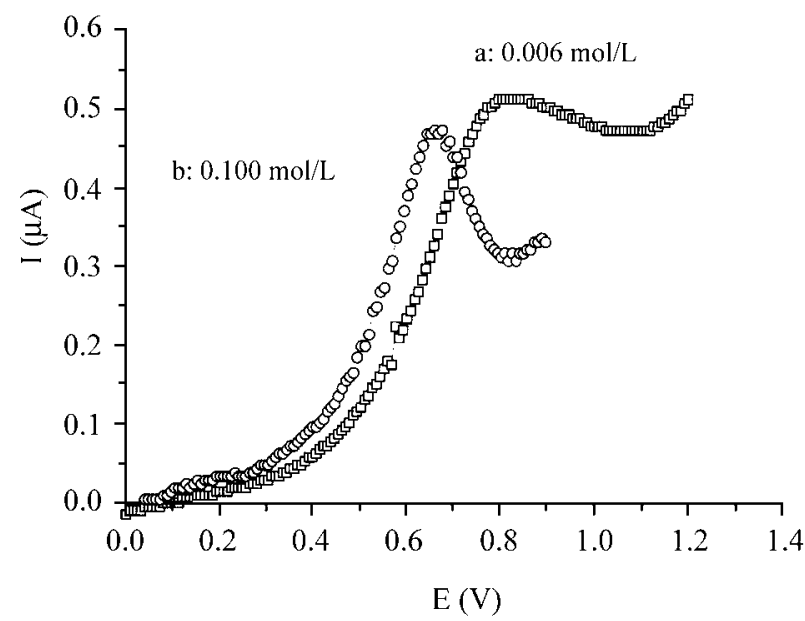

Figure 4. Anodic voltammograms $(5 \mathrm{mV} / \mathrm{s})$ of a P3MeT film $(0.45$ $\mu \mathrm{m}$ ) in acetonitrile, $0.1 \mathrm{~mol} / \mathrm{L} \mathrm{LiClO}_{4}$ : (a) $0.006 \mathrm{~mol} / \mathrm{L}$, (b) 0.100 $\mathrm{mol} / \mathrm{L}$. where $\mathrm{L}$ is the thickness of the film, and the first term is the final uniform concentration given by Ip $\tau$ / FL. These equations were solved by standard numerical integrations, using $\mathrm{x}=0$ for the last one. The program for generating simulated chronopotentiograms was written in FORTRAN 77. On average, the parameters used were 1000 intervals for the distance, 150 terms for the summation, and 200 time increments.

The pulse and the current parameters are known, and the thickness, L, is evaluated from the polymerization charge, $\mathrm{Q}_{\mathrm{p}}$, as ${ }^{12}$ :

$$
\begin{aligned}
& \text { P3MeT: } L(\mathrm{~cm})=2 \times 10^{-4} \cdot Q_{p}\left(\mathrm{C} \mathrm{cm}^{-2}\right) \\
& \text { PPy: } L(\mathrm{~cm})=4 \times 10^{-4} \cdot Q_{p}\left(\mathrm{C} \mathrm{cm}^{-2}\right)
\end{aligned}
$$

The open circuit potential $\mathrm{E}_{\mathrm{oc}}$-time experimental transients were fitted using an empirical potential-concentration relation derived from low speed cyclic voltammograms as follows: the initial anodic current curve was integrated in a $200 \mathrm{mV}$ range $\left(\mathrm{Q}_{\mathrm{a}}\right)$, the capacitive contribution $\left(\mathrm{Q}_{\mathrm{C}}\right)$ was substracted assuming ${ }^{11}$ an average double layer capacitance $\left(\mathrm{C}_{\mathrm{d}}\right)$ of $35 \mu \mathrm{F} \mathrm{cm} \mathrm{cm}^{-2}$, and the species concentration $\mathrm{C}$ was deduced from the faradic resulting change $\left(\mathrm{Q}_{\mathrm{F}}\right)$ :

$$
Q_{a}=\int_{E_{i}}^{E_{F}} \frac{i}{v} d E
$$

where $v$ is the potential sweeping speed and $\mathrm{E}_{\mathrm{F}}-\mathrm{E}_{\mathrm{i}}$ is equal to $200 \mathrm{mV}$.

$$
\begin{aligned}
Q_{c} & =\left(E_{f}-E_{i}\right) C_{d} \\
Q_{f} & =Q_{a}-Q \\
C & =\frac{Q_{F}}{F L}
\end{aligned}
$$

Finally, the apparent diffusion coefficient, $\mathrm{D}_{\mathrm{ap}}$, was obtained by matching experimental and simulated transients (see, for example, Fig. 6).

\section{Doping level evaluation}

First, it is important to know that this determination is delicate because it can be related to the ionic dopant content or to the cyclable dopant concentration, which is not necessarily the same quantity. In addition, the latter includes a low trapped ionic fraction (capacitive) and a deeper trapped one (faradic) ${ }^{13}$. Two distinct attempts were performed in order to approach this problem: an electrochemical method (in situ) integrating the low speed voltammogram, and another one using an electronic microprobe (ex situ) to dose $\mathrm{Cs}, \mathrm{S}$, and $\mathrm{Cl}$ atom contents in Cs-doped films. The latter method indicated a dopant concentration varying from $30 \%$ in the oxidized state (film 
equilibrated at $0.8 \mathrm{~V})$ to $20 \%$ in the reduced state $(-0.8 \mathrm{~V})$, while the electrochemical charge varied in the $20 \%$ range. This result shows the difficulty in identifying the actual electrochemical species, but suggests the existence of two ionic dopants besides the immobilized cation in the redox process. Moreover, it appears that only a fraction of the dopant content is involved electrochemically, as previously published ${ }^{14}$.

\section{The PPy case}

Voltammetric behavior is sensitive to the nature of the dopant ${ }^{13}$. It has already been demonstrated that for large size anionic dopants, the first process is associated with the cation motion ${ }^{14}$. For the alkaline series used in this work, it seems that the cation affects the thermodynamics of the reaction (see Fig. 2), possibly due to a contribution to site interactions ${ }^{15}$, as the nature of the dopant appears to have little effect on the electronic structure, as reported elsewhere ${ }^{16}$.

The general equation of the redox reaction can be written as follows ${ }^{17}$ :
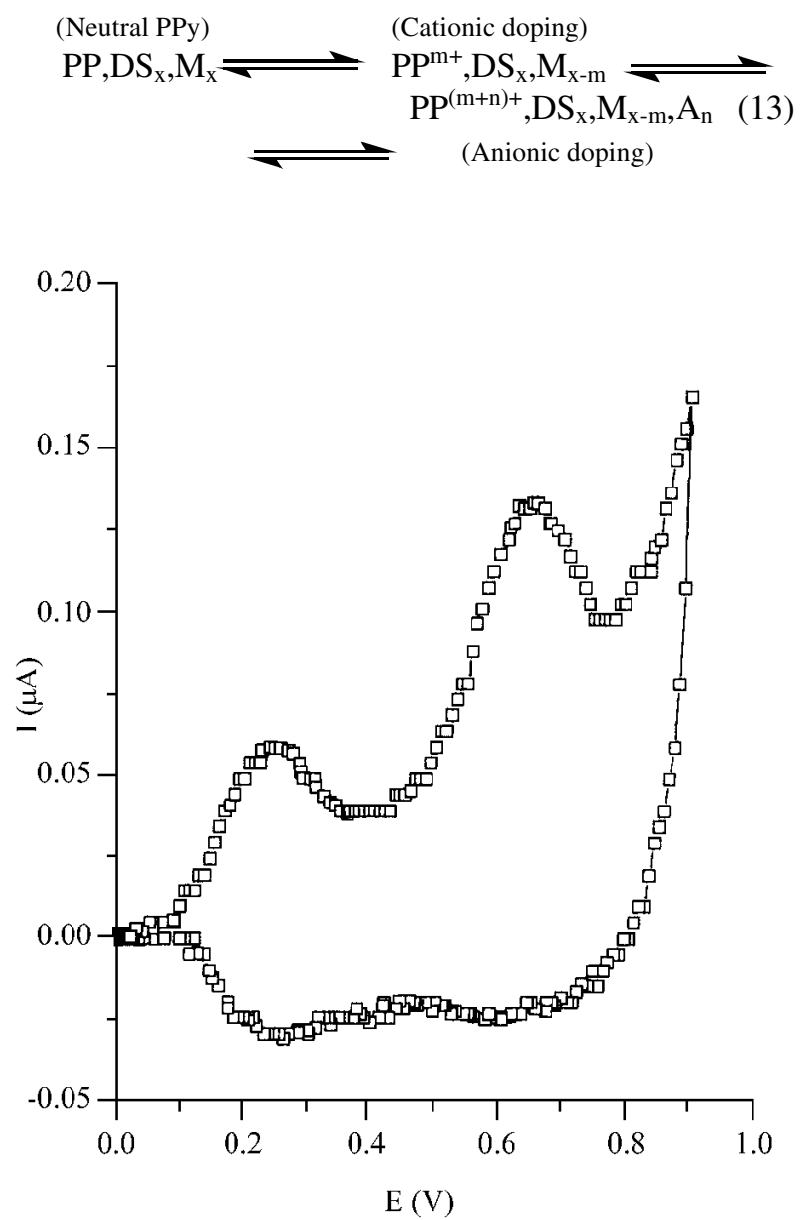

where PP is the active site of PPy as defined before, DS is the tensio-active anion (dodecylsulfate), $\mathrm{M}$ the alkaline cation, and $\mathrm{A}$ the anion of the cycling electrolyte (generally $\mathrm{Cl}^{-}$).

The kinetics of the first doping process was investigated by pulse chronopotentiometry and treated as seen in a previous section, assuming that the rate of the charge transport is controlled by cation motion ${ }^{10}$. As expected, the larger the hydratation radius of the ion, the lower / the diffusion coefficient. This feature is exemplified in Fig. 3 for two different cations of the alkaline series. Suprisingly, low values of the diffusion coefficient were obtained as compared to the literature values, but it is important to remember that we characterized the diffusional process in the reduced polymer, which is not generally the case when large amplitude methods are used. We characterized a distinct phenomena. Calculating $\mathrm{D}_{\mathrm{ap}}$ in the $\mathrm{NaCl}$ case from the slope of $\mathrm{i}_{\mathrm{pa}}-\mathrm{v}^{1 / 2}$ (voltammograms between 50 and $500 \mathrm{mV} / \mathrm{s}$ ), a value of $1.3 \times 10^{-10} \mathrm{~cm}^{2} \mathrm{~s}^{-1}$ was effectively deduced.

\section{The P3MeT case}

It has been suggested that the electrolyte concentration may have an influence on the redox properties of the conducting polymers ${ }^{12}$. As can be seen in Fig. 6, the anodic potential changed significant from $0.65 \mathrm{~V}$ at $0.1 \mathrm{~mol} / \mathrm{L}$ to 0.79



Figure 5. (5-a) Cyclic voltammograms ( $5 \mathrm{mV} / \mathrm{s}$ ) of a P3MeT film $(0.15 \mu \mathrm{m})$ in acetonitrile, $0.1 \mathrm{~mol} / \mathrm{L} \mathrm{LiClO}_{4}$. (5-b) A comparison between simulated and experimental voltammograms: $\mathrm{E}_{1}^{0}=0.24 \mathrm{~V}, \mathrm{E}_{2}^{0}=0.62 \mathrm{~V}, \mathrm{~B}_{11}=0.0095 \mathrm{~V}, \mathrm{~B}_{12}=0.015 \mathrm{~V}, \mathrm{~B}_{21}=0.0095 \mathrm{~V}, \mathrm{~B}_{22}=0.015 \mathrm{~V}, \mathrm{v}=5 \mathrm{mV} / \mathrm{s}$. 


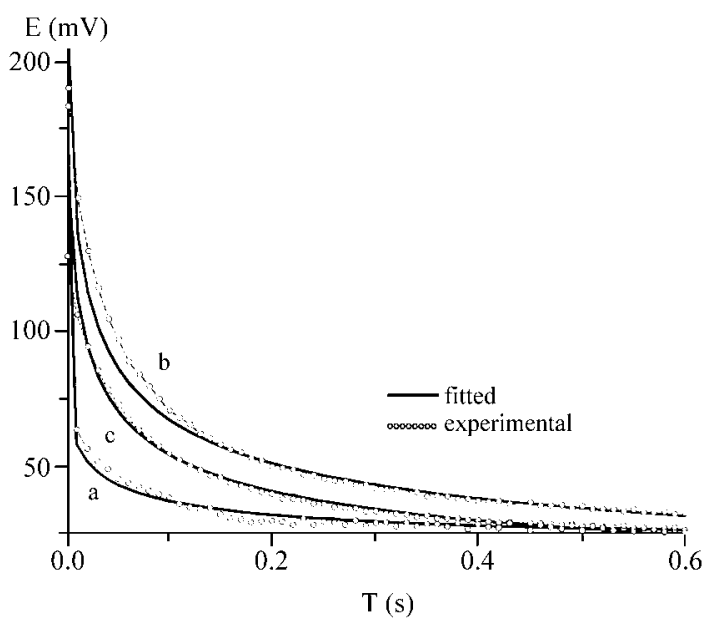

Figure 6. A comparison between simulated and experimental chronopotentiograms $\left(\tau=0.01 \mathrm{~s}, \mathrm{i}_{\mathrm{p}}=75 \mu \mathrm{A} / \mathrm{cm}^{2}\right)$ of P3MeT film in acetonitrile, $0.1 \mathrm{~mol} / \mathrm{L} \mathrm{LiClO}_{4}$ of (a) $0.15 \mu \mathrm{m}\left(\mathrm{D}_{\mathrm{ap}}=1.25 \times 10^{-10}\right.$ $\mathrm{cm} / \mathrm{s})$ (b) $1.35 \mu \mathrm{m}\left(D_{\text {ap }}=8 \times 10^{-12} \mathrm{~cm} / \mathrm{s}\right)(\mathrm{c}) 0.45 \mu \mathrm{m}\left(D_{\text {ap }}=\right.$ $\left.3.50 \times 10^{-12} \mathrm{~cm} / \mathrm{s}\right)$.

$\mathrm{V}$ at $6 \times 10^{-3} \mathrm{~mol} / \mathrm{L}$ (note that the cathodic counterpart moves too, so that it is not a conductivity effect). Kinetic measurements were also performed to detect an eventual concentration effect. However, except for the displacement of the equilibrium potential, probably due to the decrease of the electrolyte conductivity, no significant change in the diffusion coefficient was detected by chronopotentiometric analysis $\left(\mathrm{D}_{\mathrm{ap}}\right.$ remained in the range of $10^{-12}$ to $10^{-11} \mathrm{~cm}^{2} \mathrm{~s}^{-1}$ ). This suggests that the residual ionic content of the film would have little effect on the ionic mobility of the dopant.

The thickness dependence of the properties was investigated, since it is a controversial subject ${ }^{18}$. The voltammetric results cleary showed the existence of two redox steps in thin films. Fitting these data using an interaction redox model $^{5}$, formal potentials were found to be 0.25 and $0.65 \mathrm{~V}$ for the cation and dication, respectively, using only low interaction potentials (10-50 mV) (Fig. 5). This is probably due to the low molecular weight of the polymer, which provides more ideal redox behavior. It was found that the apparent diffusion coefficient decreases initially with the thickness, and then stabilizes above a certain value. According to Martin et al. ${ }^{11}$, this could result from the densification of the polymer/electrode interface due to late reacting monomer. This point is not in contradiction with the increase of porosity of the thicker films, since in this kind of experiment only the limiting step near the electrode is determining.

\section{Conclusion}

The redox properties of some conducting polymers were investigated, and PPy and P3-MeT were chosen as examples for this study. A special small amplitude method was used to characterize the kinetic limitation of the redox process, while cyclic voltammetry allowed the investigation of the thermodynamic changes. It was concluded that under our experimental conditions the ionic diffusion coefficient decreases with the thickness of the polymer film and it is slightly influenced by the electrolyte concentration. Focusing on the cationic doping of PPy, it was possible to observe a change in the diffusion speed as a function of the ionic radius of the dopant. Work is in progress on the oxidized form of the polymer, which behaves electrochemically as a porous semiconducting electrode.

\section{Acknowledgments}

Financial support from the Pró-Reitoria de Pesquisa of the Universidade Federal de Minas Gerais is gratefully acknowledged. The authors are also indebted to Prof. Armando L. de Oliveira for permitting the electrochemical measurements, and to Dr. Tullio Matencio for computational help. L.C.S. and J.C.B. wish to thank CNPq (Brazil) for their grants.

\section{References}

1. Handbook of conducting polymers; Skotheim, T.A., Ed; Marcel Dekker, New York, 1986.

2. Proceeding of the International Conference of Science and Technology, Synth. Met. 1993, 57/1.

3. Daum, P.; Lenhard, J.R.; Rolison, D.; Murray, Royce W. J.Am.Chem.Soc. 1980, 102, 4649.

4. Perlmutter, D.D.; Scrosati, B. 1988, 27, 115.

5. Pernaut, J.M.; Vieil, E.; Genies, E.; Nechtschein, M.; Travers, J.P.; Genoud, F. Synth. Met. 1986, 15, 59.

6. Bauerle, P.; Segelbacher, P.; Mehring, M.; Gaudl, K.U.; Huttenlocher, D. Angew. Chem. Int. Ed. Engl. 1993, 32, 76.

7. Otero, T.F.; Larreta, E. de Synth. Met. 1988, 26, 79.

8. Pernaut, J.M. Unpublished results.

9. Chidsey, C.E.D.; Murray, R.W. Science 1986, 231, 25

10. Faulkner, L.R.; Majda, M. J. Electroanal. Chem. 1982, 137, 149.

11. Martin, C.R.; Penner, R.M.; Van Dyke, L.S. Phys. Chem. 1988, 92/18, 5274.

12. Pernaut, J.M.; Genies, E. Synth. Met. 1985, 10, 117.

13. Tanguy, J.; Mermilliod, N.; Hoclet, M. J. Electrochem. Soc. 1987, 134/4, 795.

14. Diaz, A.F.; Castillo, J.I.; Logan, J.A.; Lee, W-Y. J. Electronal. Chem. 1981, 129, 115.

15. Bussac, M.N.; Zuppirolli, L. Phys. Rev. B 1994, 49, 5876.

16. Scahrifker, B.R.; Fermín, D.J.; Termel, H. J. Electroanal. Chem. 1996, 401, 207

17. Paoli, M.A.de; Peres, R.C.; Torresi, R.M. Synth. Met. 1992, 48, 259.

18. Osaka, T.; Naoi, K.; Ogano, S. J. Electrochem. Soc. $1987,134 / 9,2096$. 